\title{
Metal toxicity in plants: How to metallophytes manage to grow?
}

\author{
B. B. Shrestha
}

Central Department of Botany, Tribhuvan University, Kirtipur, Kathmandu, Nepal

Some of the metals (e.g. Cu, Mg, Mn etc.) are essential micronutrients of plants but other metals (e.g. $\mathrm{Pb}, \mathrm{Cr}$, $\mathrm{Ni}$ etc.) are non essential. Higher concentration of both essential and non essential metals are toxic to the plants. However, some plants called metallophytes, can grow in metal rich soil. Resistance to metal may involve exclusion from protoplast or detoxification and storage of metals in relatively inert sites such as vacuole. An understanding of genetic and physiological basis of the process involved in detoxification of metals is important in agriculture, afforestation etc. Cellular mechanisms of metal detoxification are briefly discussed.

\section{Introduction}

There is a wide range of habitat in biosphere, ranging from fresh water spring to saline water in aquatic ecosystem and marshy land to arid region in terrestrial ecosystem. Due to some anthropogenic activities such as mining, disposal of industrial waste, agricultural practices etc, physico-chemical characters of soil has been changed to such an extent that it is unsuitable for growth of many plants. The rapid change in environmental condition is likely to override the adaptive potential of plants, specially that of tree species with their long reproductive life cycles. Some plants growing in such extreme conditions evolve different strategies to ameliorate the effect of environmental stress. Absorption of water for halophyte, storage of water in xerophyte, resistance to metal toxicity in metallophytes etc. are few examples of strategies used by plants growing in respective habitat. Understanding the mechanisms of these strategies and improving plants' protections against stress are important fields of research in ecophysiological study.

Heavy metals are characterized by their higher density, being greater than $5 \mathrm{~g} / \mathrm{ml}$ (Lambers et al. 1998). Heavy metals such as copper $(\mathrm{Cu})$, cobalt $(\mathrm{Co})$, iron $(\mathrm{Fe})$, manganese $(\mathrm{Mn})$, molybdenum (Mo), and zinc ( $\mathrm{Zn})$ are essential micronutrients necessary for normal growth and development since they are important constituents of many enzymes (as co-factor or activator) and other proteins. However, higher concentrations of these essential and non-essential (cadmium Cd, chromium $\mathrm{Cr}$, lead $\mathrm{Pb}$, gold $\mathrm{Au}$, mercury $\mathrm{Hg}$, silver $\mathrm{Ag}$, and uranium $\mathrm{U}$ ) heavy metals in soil are toxic and inhibit growth of most plants. Toxicity in plants may results from binding of metals to proteins leading to inhibition of activity, or from displacing of essential element resulting of deficiency effect, or stimulating the formation of free radicals and reactive oxygen species resulting in oxidative stress (Lambers et al. 1998, Hall 2002).
Metallophyte is a group of plants, which can grow in soil rich in certain metals. They can grow in such soil not because they need higher concentration of metal but because they can resist higher concentration. Resistance to heavy metal involves avoidance and tolerance. In avoidance plant avoid the absorption while in tolerance they detoxify and sometimes accumulate the metals on or inside the cell. Hyper-accumulation raises important biological questions such as the mechanisms by which toxicity is avoided and the possible adaptive significance of such high level of heavy metals (Psaras et al. 2000). An understanding of genetic and physiological basis of the process involved in detoxification of heavy metals is an essential pre-requisite in the development of crop for phyto-remediation of heavy metals, in selecting appropriate species and breeding suitable varieties for re-vegetation of highly contaminated soil and for selecting bio-indicator plants (Larcher 1995, Salt et al. 1998).

\section{Sources of heavy metals}

Environment of plant receives heavy metals from geological (natural) or anthropogenic sources. Serpentine soil naturally have high levels of $\mathrm{Ni}, \mathrm{Cr}, \mathrm{Co}$ and $\mathrm{Mg}$. Higher level of metals is also found in soil covering ore bearing rock. Anthropogenic sources involve slag from metal extraction plants (e.g., As, Cd, $\mathrm{Co}, \mathrm{Cr}, \mathrm{Cu}, \mathrm{Mn}, \mathrm{Pb}, \mathrm{Zn}$ ), waste water from factories (e.g., $\mathrm{Cd}$, $\mathrm{Cr}, \mathrm{Cu}, \mathrm{Fe}, \mathrm{Hg}, \mathrm{Pb}, \mathrm{Zn}$, etc.), heavy vehicular traffic (e.g., $\mathrm{Pb}$ ), garbage and sewage slug (e.g., $\mathrm{Cd}, \mathrm{Cr}, \mathrm{Cu}, \mathrm{Fe}, \mathrm{Hg}, \mathrm{Ni}, \mathrm{Zn}$ ), strongly acidic soil (e.g., Al) etc. (Larcher 1995). The metals enter into the plant from soil through root. But mercury in leaves of red pine (Pinus resinosa Ait.) is directly derived from atmosphere (Fleck et al. 1999). Atmospheric mercury may enter through stomata or it may be deposited on leaf surface as particulate mater, which ultimately reaches to internal tissue.

\section{Nature of metal toxicity}

The toxicity of heavy metal ions is due chiefly to inactivation of vital enzymes and their interference with electron transport 
Figure 1. Summary of potential mechanisms available for metal detoxification and tolerance in higher plants. 1. Restriction of metal movement to roots by mycorrhizas. 2. Binding to cell wall and root exudates. 3 . Reduced influx across plasma membrane. 4. Active efflux into apoplast. 5. Chelations in cytosol by various ligands. 6. Repair and protection of plasma membrane under stress conditions. 7. Transport of PC-Cd complex into the vacuole. 8. Transport and accumulation of metals in vacuole. (After Hall 2002).

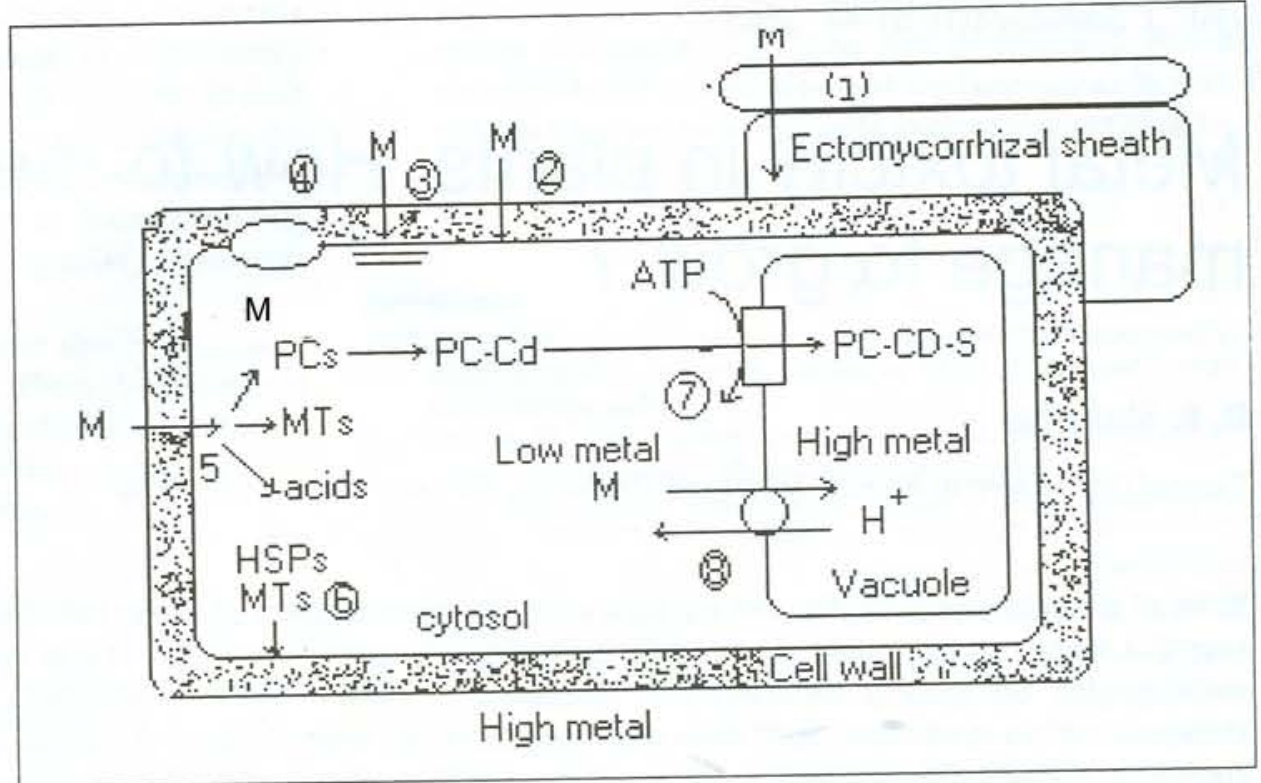

in respiration and photosynthesis. (Larcher 1995). Heavy metals create long-term problem because they not only accumulate in organism and circulate in food chain but also remain in ecosystem in dangerous concentration for longer period in sediment. Some of the heavy metals are necessary for plants at very lower concentration but most of the plants cannot prevent the entry of heavy metals in excess amount. Other non-essential toxic heavy metals also enter the plant by similar mechanisms.

Mechanisms of metal toxicity have not been known in detail. Based on their chemical and physical properties three different molecular mechanisms of heavy metal toxicity can be distinguished: a) production of reactive oxygen species, b) blocking of essential functional groups in bio-molecules, and c) displacement of essential metal ions from bio-molecules (Schutzendubel and Polle 2002). There are direct evidences for nature of toxicity of few metals like $\mathrm{Cu}$ and $\mathrm{Al}$ but for other metals like $\mathrm{Zn}$, Cd, etc this has been inferred from indirect evidences. $\mathrm{Cd}$ reduces ATPase activity of plasma membrane while $\mathrm{Cu}$ toxicity leads to increased efflux of $\mathrm{K}^{+}$from root by changing cell permeability, damage to cell membrane by oxidation of proteins, inhibition of key membrane protein such as $\mathrm{H}^{+}$-ATPase or changes in the composition and fluidity of membrane lipid (Hall 2002). Cu has also been found to reduce the amount of chlorophyll-a and total chlorophyll in lichens (Chettri et al. 1998) and thereby hampers photosynthesis. $\mathrm{Ni}$ is known to suppress photosynthetic electron flow and to impair photosynthetic activity by substituting $\mathrm{Mg}$ in chlorophyll molecules (Psaras et al. 2000). Zn may replace Mg in Rubisco, reducing the activity of this enzyme and hence the photosynthetic capacity. $\mathrm{Zn}$ toxicity may also be due to binding of this metal with water channel protein of plasma membrane leading to reduced water up take (Lambers et al. 1998 and references therein).

$\mathrm{Al}$ is the most abundant and toxic light metal, and is available to plants as the free $\mathrm{Al}^{3+}$ ions under acidic condition. $\mathrm{Al}$ accumulates predominantly in the cells located within the apical elongation zone in plant roots and inhibits cell elongation rapidly. $\mathrm{Al}$ accumulated on the outer plasma membrane may effect mitochondria functions by an unknown signal transduction pathway while a small amount of Al transported across the plasma membrane may directly interfere with mitochondrial functions (Yamamoto et al. 2002). Production of reactive oxygen species (presumably $\mathrm{O}^{2-}$ ), respiration inhibition and ATP depletion seem to be critical events of Al toxicity in cultured plant cell and whole root. Al triggered hindrance of an electron flow leads to the inhibition of normal oxygen consumption by cytochrome oxidase (respiration inhibition), but to the enhancement of $\mathrm{O}^{2-}$ production by the leakage of electrons directly to oxygen. So it is likely that $\mathrm{O}^{2-}$ production is a key critical event leading to the loss of growth capability.

\section{Resistance to toxic metals}

Plants growing in contaminated soil, which develop the ability to resist higher level of heavy metals, are the chemo-ecotype. The ability to resist heavy metals is genetically determined and can also be modified by adaptation. Chemo-ecotypes develop the ability to resist higher concentration of heavy metal in their tissue when they grow on contaminated soil. This ability increases with greater exposure to such elements. Some species have higher degree of genetic plasticity and can resist many heavy metals (Larcher 1995). For example Agrostis tenuis and Plantago lanceolata are resistant to $\mathrm{Zn}, \mathrm{Cu}, \mathrm{Cd}$, and $\mathrm{Ni}$.

Although in many plants resistances is due to exclusion of the metal from the protoplast, some plants actively take up metals leading to accumulation at extremely higher level, exceeding those in the soil. Such plants are called hyper accumulators. In Ni-hyper-accumulators (Alyssum spp, Bornmuellera spp and Thlaspi pindicun) it is deposited in leaf epidermis. However it is excluded from guard cells and trichomes, and is sequestered in physiologically more inert, yet living cells (Psaras et al. 2000.) The absence of $\mathrm{Ni}$ from mesophyll and guard cells can be correlated with its deleterious effect in photosynthesis. In seeds of hyper-accumulating species Thaspi pindicum Hausskn (Brassicaceae), Ni preferentially accumulates in micropylar area opposite the radicle and in the 


\section{Table - 1. Summary of potential mechanisms involved in the detoxification of and tolerance to specific metals.}

\begin{tabular}{ll}
\hline Mechanism & Metals \\
\hline Plant-mycorrhizal association & $\mathrm{Zn}, \mathrm{Cu}, \mathrm{Cd}$ \\
\hline Cell wall, root exudates & $\begin{array}{l}\text { various metals including } \\
\mathrm{Ni}, \mathrm{Al}\end{array}$ \\
\hline $\begin{array}{l}\text { Plasma membrane } \\
\text {-Reduced uptake }\end{array}$ & Arsenate, $\mathrm{Ni}$ \\
$\quad$-Active efflux & various including $\mathrm{Zn}$ \\
\hline Phytochelatin & $\mathrm{Cd}$ \\
\hline Metallothioneins & $\mathrm{Cu}$ \\
\hline Heat shock proteins & various including $\mathrm{Cd}$ \\
\hline Vacuolar campartmentation & $\mathrm{Zn}$ \\
\hline
\end{tabular}

epidermis of cotyledon (Psaras and Manetas 2001). Micropyle is the point of entry of radical-consuming frugivores. Accumulation of $\mathrm{Ni}$ at micropylar region may be an elemental chemical defense. This is in compatible to the antiherbivore role ascribed to metal hyper-accumulation (Boyd 1998).

A successful detoxification of heavy metals requires the formation of a stable organo-metallic complex (e.g. complex of $\mathrm{Ni}$ with citrate and malate) and physiologically inert cell compartment for permanent storage (Brooks 1998). Strategy adopted by the plant is to avoid metal accumulation in cytosol which may involve reduced uptake into the cytosol, chelation of metal in cytosol or efflux from cytosol, either into apoplast or into vacuole (Hall 2002). It is possible that more than one mechanisms may be involved in reducing the toxicity of a particular metal. A summary of potential cellular mechanisms for metal detoxification and tolerance in higher plants is presented in Figure 1. Different mechanisms are briefly described below.

\section{Mycorrhizas}

Mycorrhizas are characteristics of many trees and shrubs. Particularly the ectomycorrhizas are effective in reducing the toxic effect of heavy metals such as $\mathrm{Zn}, \mathrm{Cu}$ and $\mathrm{Cd}$ to the host plant. Most mechanisms that have been proposed to explain the role of ectomycorrhizas in metal resistance involve the exclusion process that restrict metal movement to host roots. It includes adsorption of hyphal sheath, reduced access to the apoplast due to the hydrophobicity of fungal sheath, chelating by fungal exudates and adsorption onto the external mycelium. Schutzendubel and Polle (2002) showed that mychorrhizal symbiosis buffered the typical Cd-induced stress but it not known whether mychorrhization protects root from $\mathrm{Cd}$-induced injury by preventing access of $\mathrm{Cd}$ to sensitive extra- or intracellular sites, or by excreted or intrinsic metal-chelators, or by other defense system.

\section{Binding to cell wall and root exudates}

The binding property of the cell wall and its role as a mechanism of metal tolerance has been a controversial one. However, accumulation of a range of metals in the epidermal cell walls (of root) of heavy metal resistant Silene vulgaris ssp. humilis has been reported (Bringezu et al 1999). Similarly, transmission electron microscopic study in lichens have revealed that most of the bioaccumulation of metals takes place in cell wall and high concentration of $\mathrm{Cu}$ may damage cell wall (Chettri et al. 2000).

Root exudates contains a range of organic compounds including organic acids (e.g. oxalic acids). They may form chelating product with heavy metal like $\mathrm{Ni}$ and non-toxic derivatives of high metals like $\mathrm{Al}$ (Al-oxalate) (Ma et al. 2001).

\section{Role of plasma membrane}

Plasma membrane is the first living structure of cell that is a target for heavy metal toxicity. Damage to the plasma membrane is the main event of toxicity of heavy metals such as $\mathrm{Cu}$ and $\mathrm{Cd}$. So tolerance involves the protection of plasma membrane against heavy metal damage. Another factor may be the efficient membrane repair system after damage. Beside these, the cell membrane may play an important role in metal homeostasis, either by preventing or reducing entry into the cell or through active efflux mechanisms. The tolerance mechanism to arsenic toxicity in Holcus lanatus is genetically determined reduced uptake of ions (Meharg and Macnair 1992). Energy dependent efflux of toxic ions through plasma membrane is another important strategy for controlling intracellular metal level. This efflux pumping system has been identified for $\mathrm{Cu}, \mathrm{Cd}, \mathrm{Co}, \mathrm{Ni}$ and $\mathrm{Zn}$ (Silver 1996). Though there is no direct evidence, recent researches show the possibility of presence of metal transporter for active efflux of toxic metal ions across plasma membrane.

Heat shock proteins (HSPs), which show increased concentration in response to higher temperature, are also expressed in response to heavy metal stress and function in the protection and repair of proteins under stress condition. $\mathrm{Cu}$ and $\mathrm{Cd}$ are known to induce greater expression of HSPs. It may have important role in tolerance mechanism involving a more resistant plasma membrane or improved repair mechanism (Hall 2002).

\section{Chelation}

Chelating of metals in the cytosol by high affinity legends is potentially a very important mechanism of heavy metal detoxification and tolerance. Potential legends involve amino acids, organic acids, phytochelatins and metallothioneins. Phytochelatins (PCs) have been most widely studied in plants in relation to $\mathrm{Cd}$ tolerance. PCs appear to be important in the detoxification of $\mathrm{Cd}$ and arsenate but play no role in the detoxification of $\mathrm{Zn}, \mathrm{Ni}$ and selenite ions (Ha et al. 1999). A possible role of PCs in $\mathrm{Cu}$ tolerance has also been proposed but it is yet to be resolved.

Phytochelatins are metal complexing peptides, which are rapidly induced in plants by heavy metal treatment. A clear role of PCs in $\mathrm{Cd}$ detoxification has been supported by biochemical and genetic evidences. In Brassica juncea it has been shown that $\mathrm{Cd}$ accumulation is accompanied by rapid induction of PCs biosynthesis which was sufficient to chelate all $\mathrm{Cd}$ taken up and this protects photosynthesis (Haag-Kerwer et al. 1999). The 
final step in Cd detoxification involves the accumulation of $\mathrm{Cd}$ PCs in vacuoles. In vacuole it is stabilized by the formation of Cd-PCs-sulphide complex (Ortiz et al. 1992).

Metallothioneins (MTs) are cytosine-rich, metal binding peptides. There are evidences for the role of MTs in heavy metal tolerance in fungi and animals and its role in $\mathrm{Cu}, \mathrm{Zn}$ and $\mathrm{Cd}$ tolerance in higher plants has been suggested but it remains to be established (Hall 2002). They may functions as anti-oxidant and may have some role in plasma membrane repair.

\section{Vacuolar compartmentation}

Transport of ions to vacuole to reduce the level of toxic metals in cytosol is potentially another important mechanism for heavy metal tolerance. In fact, vacuoles are the site for accumulation of a number of heavy metals including $\mathrm{Zn}$ and Cd (De 2000).

$\mathrm{Zn}$ indices increased vacuolation in meristematic cell and rapid sequestration of $\mathrm{Zn}$ into the vacuoles. At higher concentration $\mathrm{Zn}$ transport across the membrane of isolated toneless vesicle is 2.5 times higher in $\mathrm{Zn}$ tolerant than that in $\mathrm{Zn}$ sensitive ecotype of Silene vulgaris (Verkleij et al. 1998). $\mathrm{Zn}$ tolerance may be genetically controlled and specific $\mathrm{Zn}$ transporter may be involved in sequestration of $\mathrm{Zn}$ in vacuoles (Chardonnens et al. 1999).

Though the mechanisms of metal toxicity and resistance have been extensively studied it is not precisely known. It is important to understand these mechanisms to improve plant's protection against metal toxicity. Toxic metal induced production of reactive oxygen species and role of mychorrhiza in detoxification of heavy metals are promising fields of research. The development of heavy metal tolerant plantmycorrhizal associations may be a new strategy for pytoremediation of metal from contaminated soil. The primary screening of Nepalese flora has not been done to assess the potentiality to resist heavy metal toxicity. Since the behavior of Himalayan plants is different from both temperate and tropics, generalization made from research of other region may not be applicable for these plants. There is urgent need to identify potential plant species to be used for phytoremediation from Nepalese Himalayan flora that has not been explored yet for this purpose.

\section{References}

Boyd, R. S. (1998). Hyperaccumulation as plant defense strategy. In: Plants that hyperaccumulate heavy metals, R. R. Brooks (Ed.), pp. 181-201. New York, USA: CAB International.

Bringezu, K., O. Lichtenberger, I. Leopold and D. Neumann (1999). Heavy metal tolerance of Silene vulgaris. Jr. of Pl. Physiol. 154: 536-546

Brooks, R. R. (1998). Geobotany and hyperaccumulators. In: Plants that hyperaccumulate heavy metals, R. R. Brooks (Ed.), 55-94. New York, USA: CAB International

Chardonnens, A. N., P. L. M. Koevocts, A. van Zanten, H. Schat and J. A. C. Verkleij (1999). Propertiies of enhanced tonoplast zinc transport in natural selected zinc-tolerant Silene vulgaris. Pl. Physiol. 120: 779-785

Chettri, M. K., C. M. Cook, E. Vardaka, T. Sawidis, and T. Lanaras (1998). The effect of $\mathrm{Cu}, \mathrm{Zn}$ and $\mathrm{Pb}$ on chlorophyll content of the lichens Cladonia convoluta and Cladonia rangiformis. Env. and Expt. Bot. 39: 1-10

Chettri, M. K., T. Sawidis and E. Weryzko-Chmielewska (2000). Localization of heavy metals in lichen thalli: an ultra-structural approach. Bios (Macedonia, Greece) 5: 61-75

De, D. N. (2000). Plant cell vacuoles. Collingwood, Autralia. CSIRO Publishing

Fleck, J. Z., D. F. Grigal and E. A. Nater (1999). Mercury uptake by trees: an observational experiment. Water, Air and Soil pollution. 115: 513-523

Ha, S. B., A. P. Smith, R. Howden, W. M. Dietrich, S. Bugg, M. J. O'Connell, P. B. Goldsbrough and C. S. Cobbett (1999). Phytochelatin synthase genes from Arabidopsis and the yeast Schizosaccharomyces pombe. The Plant Cell 11: 1153-1163

Haag-Kerwer, A., H. J. Schafer, S. Heiss, C. Walter and T. Rausch (1999). Cadmium exposure in Brassica juncea causes a decline in transpiration rate and leaf expansion without effect of photosynthesis. Jr. of Expt. Bot. 50: $1827-1835$

Hall, J. L. (2002). Cellular mechanism for heavy metal detoxification and tolerance. Jr. of Expt. Bot. 53 (366): 1-11

Lambers, H., F. S. Chapin III and T. L. Pons (1998). Plant physiological ecology. Springer-Verlaag, New York Inc

Larcher, W. (1995). Physiological plant ecology. Springer-Verlag, Berlin Germany

Ma, J. F., P. R. Ryan and E. Delhaize (2001). Aluminium tolerance in plants and the complexing role of organic acid. Trends in Plant Science 6: 273278

Meharg, A. A. and M. R. Macnair (1992). Genetic correlation between arsenate tolerance and the rate of influx of arsenate and phosphate in Holcus lanatus. Heredity 69: 336-341

Ortiz, D. F., L. Kreppel, D. M. Speiser, G. Scheel, G. Mcdonald and D. W. Ow (1992). Heavy metal tolerance in fission yeast requires an ATP-binding cassette-type vacuolar membrane transporter. EMBO Journal 11: 3491 3499

Psaras, G. K. and Y. Manetas (2001). Nickel localization in seeds of the metal hyper accumulator Thlaspi pindicum. Hausskn. Ann of Bot 88: 513-516

Psaras G. K., T. H. Constantinidis, B. Cotsopoulos and Y. Manetas (2000). Relative abundance of Nickel in the leaf epidermis of eight hyper accumulators: Evidence that the metal is excluded from both guard cells and trichomes. Ann. of Bot. 86: $73-78$

Salt D. E., R. D. Smith and I. Ruskin (1998). Phytoremediation. An. Rev. of Pl. Physiol. and Pl. Mol. Bio. 49: 643 - 668

Schutzendubel, A. and A. Polle (2002). Plant responses to abiotic stress: heavy metal induced oxidative stress and protection by mychorrhization. $\mathrm{Jr}$. Expt. Bot. 53(372): 1351-1365

Silver, S. (1996). Bacterial resistance to toxic metal ions - a review. Gene 179: 9-19

Verkleij, J. A. C., P. L. M. Koevoefs, M. A. Mechteld, M. M. A. Blake-Kalff and A. N. Chardonnens (1998). Evidences of an important role of the tonoplast in the mechanism of naturally selected zinc tolerance in Silene vulgaris. Jr. of Pl. Physiol. 153: 188-191

Yamamoto, Y, Y. Kobayashi, S. R. Devi, S. Rikiishi and H. Matsumoto (2002). Aluminium toxicity is associated with mitochondria dysfunction and the production of reactive oxygen species in plant cells. Pl. Physiol 128: 63-72 